\title{
O NÃO DITO NA OBRA DE ARHUR RAMOS
}

\author{
Ulisses Neves Rafael ${ }^{*}$
}

\begin{abstract}
Resumo: O objetivo deste artigo é discutir à luz da obra de Arthur Ramos, sobretudo dos estudos antropológicos voltados à compreensão das religiões afro-brasileiras, a razão pela qual esse autor alagoano teria dedicado tão pouca atenção aos xangôs de sua terra, tendo feito menção à perseguição sofrida pelas casas de culto de Maceió em 1912, apenas superficialmente e sem a preocupação de avançar sobre as motivações daquele episódio que a crônica local batizou de "Operação Xangô" e que ficou tão marcado na memória dos seus praticantes.
\end{abstract}

Palavras-chave: Arthur Ramos; Operação Xangô; religiões afrobrasileiras.

\section{Introdução}

O objetivo desta reflexão é trazer a lume as contribuições de Arthur Ramos acerca das religiões afro-brasileiras, mas com uma preocupação em particular: compreender as razões da superficialidade ou mesmo das lacunas encontradas em suas análises acerca do culto do xangô ${ }^{1}$ em Alagoas e, mais especificamente, sobre o "quebra de 1912", episódio que implicou a devassa nos terreiros de Maceió e cidades vizinhas naquele ano e que tantas consequências acarretou para a memória e a continuidade dessas práticas religiosas no Estado.

\footnotetext{
* Doutor em Sociologia e Antropologia pela Universidade Federal do Rio de Janeiro, professor adjunto da Universidade Federal de Sergipe e, atualmente, investigador associado do Centro de Estudos Sociais da Universidade de Coimbra, onde realiza Estágio PósDoutoral.
} 
O interesse pela temática remete ao período das investigações sobre a "Operação Xangô", outro nome pelo qual também ficou conhecida a invasão das casas de culto alagoanas, tendo resultado na tese de doutorado intitulada Xangô rezado baixo: um estudo da perseguição aos terreiros alagoanos em 1912 (Rafael, 2004). O desafio posto era o de superar a ausência de fontes documentais sobre a questão das religiões de procedência africana em Alagoas, bem como de uma bibliografia especializada sobre a temática ou sobre o quebra especificamente. A perspectiva era poder encontrar nesse grande antropólogo alagoano as chaves para a compreensão desse fatídico 2 de fevereiro de 1912, quando as ruas de Maceió foram tomadas por integrantes de uma milícia particular, conhecida como a Liga dos Republicanos Combatentes, responsável pela invasão e destroçamento das principais casas de culto daquela capital e de municípios vizinhos.

Ressalte-se que essa exiguidade de fontes documentais sobre um acontecimento que teve consequências tão decisivas para a história das religiões de procedência africana no Estado é, no mínimo, curiosa. Tal lacuna causa mais inquietação ainda quando se leva em conta toda a tradição antropológica alagoana, que conta, entre outros, com nomes consagrados como Manoel Diégues Júnior, Théo Brandão e, principalmente, Arthur Ramos, sem dúvida, dentre os três, o que maior projeção conseguiu fora do seu Estado natal. Assim, o tema do silêncio ocupa uma posição central nessa discussão, sobretudo, se se considerar o fato de que essa mesma atitude a que se recolheu a intelectualidade alagoana com relação ao assunto reflete o modelo cerimonial reservado que passou a predominar nos próprios terreiros, obrigados que foram seus responsáveis a uma reelaboração dos seus cultos, adotando uma modalidade distinta de cerimonial, marcadamente discreta e fechada.

Gonçalves Fernandes (1941), em visita a Alagoas, testemunhou a existência ainda dessa modalidade de culto, que ele designou, 
entre outros termos, de "Candomblé em silêncio", tendo dedicado ao assunto, todo o primeiro capítulo do seu livro $O$ sincretismo religioso no Brasil, intitulado, "Uma nova seita afro-brasileira: o Xangô-rezado-baixo", onde trata da sua incursão a algumas casas de culto de Maceió em junho de 1939, portanto, quase trinta anos depois da fatídica "Operação Xangô".

\section{O quebra de 1912 e o silêncio a respeito}

Esse episódio que também se convencionou chamar "Quebra-quebra" teria ocorrido na madrugada do dia 2 de fevereiro. Vale ressaltar que, na época, esse era um dia santificado, em homenagem à purificação de Nossa Senhora ou Imaculada Conceição, sendo que alguns terreiros dedicavam a data à celebração de Oxum, orixá do panteão afro-brasileiro.

Nesse período, o governador do Estado, Euclides Malta, se encontrava afastado do poder, de onde fora retirado poucos dias antes, a 29 de janeiro, por revoltosos populares capitaneados pela Liga dos Combatentes. Os motivos alegados fora a sua longa permanência no poder, já que teria exercido três mandatos (1900/1903, 1906/1912), tendo sido substituído em período intermediário pelo irmão, Joaquim Paulo Vieira Malta (1903/1906), fato que concorreu para caracterizar essa época como a "era dos Malta". Segundo os adversários políticos, essa longevidade da família decorria da proteção obtida junto às casas de feitiço da capital, razão pela qual se decidiu também atacálas, mesmo quando o governador deposto não ameaçava mais os planos da oposição.

Segundo o órgão oposicionista Jornal de Alagoas, que, na época, publicou uma série de matérias intituladas "Bruxaria", a devassa em mais de trinta dessas casas espalhadas pela cidade contou com a participação de mais ou menos duas mil pessoas, sendo que quinhentas delas foram ao terreiro de Tia Marcelina, um dos mais 
antigos da capital. Esse fato que até hoje se inscreve na crônica dos cultos afro-brasileiros como um dos mais violentos de que foi vítima essa modalidade religiosa no Brasil, provocou a diáspora de pais, mães e filhos de santo, os quais recorreram aos Estados vizinhos da Bahia e Pernambuco, a fim de dar prosseguimento às suas atividades. Os poucos que permaneceram em Alagoas, como os que foram localizados por Gonçalves Fernandes em 1937, já haviam desenvolvido uma modalidade especifica de culto, o "xangô rezado baixo" que, como o próprio nome sugere, consiste num tipo de cerimonial que visava dissimular tais práticas:

As cerimônias, muito fechadas, sem dansas (...) sem música, sem a exaltação efetiva da música dos encantados negros, sem o 'toque', as cerimônias se passam num tom de reza ciciada. Não existe mais o 'terreiro', que hoje é uma sala-de-visitas, nem o 'peji', desaparecido. Foram-se os objetos litúrgicos, e só aparece de resto, muito singularmente, uma curta haste de madeira em forma de x deitado: é uma forma mais remota de um 'oxe' de Xangô que desponta, último fetiche da espécie neste candomblé-em-silêncio. (Fernandes, 1941, p. 9-10). ${ }^{2}$

\section{A contribuição de Arthur Ramos para os estudos das religiões afro-brasileiras}

Voltando, pois, ao argumento inicialmente proposto, foi em decorrência desse silêncio que se optou por tratar da contribuição de Arthur Ramos à compreensão das dinâmicas dos xangôs alagoanos, bem como para esclarecer as inquietações suscitadas pelo quebra de 1912. Desse modo, a retomada que se faz aqui da sua obra tem a finalidade de questionar os motivos do seu silenciamento sobre aquele episódio.

Ao reler o trabalho clássico desse antropólogo alagoano, $O$ negro brasileiro, mais especificamente a edição organizada pela Fundação Joaquim Nabuco, verificou-se no prefácio, escrito por 
René Ribeiro, uma importante observação acerca de um traço já conhecido da trajetória intelectual de Artur Ramos, mas pouco explorado pelos analistas de plantão, qual seja, "suas andanças pelos candomblés da Bahia". Essa sua inserção pelas casas baianas, no entanto, vai além da mera curiosidade. A certa altura dos estudos realizados, Arthur Ramos decide ingressar de modo mais efetivo nesses espaços religiosos, assumindo a função de ogã no terreiro do Gantois com a finalidade exclusiva de pesquisa, como ele mesmo fez questão de frisar no estudo sob análise. ${ }^{3}$ Essa prática, inaugurada por Nina Rodrigues, feito ogã de Oxalá por mãe Pulquéria, também do terreiro de Gantois, viria a se tornar corrente entre os antropólogos, sobretudo após os anos 40, quando aí, então, a iniciação não se justificativa apenas em termos de "necessidades técnicas". Roger Bastide, por exemplo, mais um que se deixou seduzir pelo mundo dos terreiros, tornou-se um ferrenho defensor de "uma metodologia de trabalho de campo na qual o pesquisador deveria não se colocar do lado de fora da experiência social de seus pesquisados, mas vivêla como se fosse sua". ${ }^{4}$

O que deve ser salientado dessa postura, pelo menos no caso de Arthur Ramos, é que, exatamente por ter assumido essa condição de ogã, muitas das informações por ele coletadas no contato com essa religião passam a ser sonegadas ou pelo menos mantidas em segredo, como se esperava de alguém que com ela mantinha laços tão íntimos. Para tanto, a descrição que nos é fornecida por esse autor em $O$ negro brasileiro é resultado de pesquisas feitas em jornais, que divulgavam, entre outras coisas, reclamações de vizinhos e a descrição das batidas policiais aos centros de candomblé, fato corriqueiro desde a época de Nina Rodrigues. ${ }^{5}$ Vejamos o que diz René Ribeiro a respeito, no dito prefácio:

Em O Negro Brasileiro, o erudito professor da Bahia, apesar de ogan, se ressente da discrição e do segredo (...) da tradição do candomblé, especialmente agudos na Bahia de então, tendo de recorrer, apesar da sua assiduidade nos terreiros, para documentação 
de cerimônias, à transcrição de reportagens como as de $A$ Tarde (Salvador) e do Jornal de Alagoas (Maceió). Ali registravam-se as apreensões pela polícia de "toda sorte de bugigangas, que são mandadas para o museu do Instituto Histórico" (...), ou noticiava-se a prisão de "pais e mães de santo", ou dava-se curso às queixas dos moradores incomodados com o barulho dos toques, ou apoiavam-se as campanhas das autoridades contra "a cartomancia e o fetichismo" ou, então, noticiavam-se as "canoas" policiais organizadas pelas autoridades baianas e alagoanas para efetivarem a "ação moralizante dos poderes competentes". (Ribeiro, 1988, p. 50).

Levando-se em conta a vasta contribuição de Arthur Ramos para o estudo do negro no Brasil, cuja obra vem suprir as lacunas por ele mesmo reclamadas em relação, principalmente, às tribos africanas introduzidas em nosso território, nota-se que, tendo abarcado os dois grandes grupos religiosos, sudaneses e bantus, introduzidos inicialmente nos Estados da Bahia e Pernambuco, respectivamente, o foco de sua análise irá se voltar, principalmente, sobre os candomblés da Bahia e sobre as macumbas do Rio de Janeiro, local para onde depois se irradiaram grandes focos do grupo banto.

Essa opção metodológica coincide com sua atividade intelectual, a qual se desenvolveu nesses dois Estados, razão pela qual talvez não se localize em seus trabalhos aquela preocupação de que se ocupou Roger Bastide (1971), em Religiões africanas no Brasil, cujo mapeamento das religiões africanas aqui existentes, objetivava cobrir todo o território nacional:

Foi em virtude da minha profissão de médico legista e clínico, que me puz em contacto, na Bahia, com as classes negra e mestiça da sua população indo surprehender, a muito custo, e após tenaz e paciente esforço, todos os mistérios das religiões negro-fetichistas e as formas de todo esse ceremonial mágico-religioso de origem africana. Transportando-me para o Rio de Janeiro (...) para installar um Serviço de Hygiene Mental nas Escolas do Districto Federal (...) puz-me a estudar a população proletária dos morros (...) e por 
ahi, progressivamente penetrei no recôndito das macumbas e dos centros de feitiçaria. (Ramos, 1988, p. 22-23)

Considerando, pois, seu vasto inquérito sobre as religiões negro-fetichistas, resultado de um interesse particular pelo sentimento religioso, o qual, segundo ele mesmo, "é o melhor caminho para se penetrar na psicologia de um povo", além dessa sua tendência voluntária para a discrição e o segredo, observa-se que, tanto nesse seu trabalho pioneiro, O negro Brasileiro, como em outro volume, intitulado Folclore negro do Brasil, Arthur Ramos irá lançar mão de valiosíssima documentação - no caso, as reportagens publicadas no noticiário da imprensa diária. No seu próprio Estado, a fonte utilizada é o Jornal de Alagoas, cuja matéria intitulada "Nos domínios da bruxaria", publicada no dia 28 de março de 1934, foi escolhida para constar no primeiro daqueles trabalhos com a finalidade de corroborar suas idéias sobre o sincretismo religioso, comum nos cultos do negro e do mestiço brasileiro de um modo geral.

Outra matéria, também retirada do mesmo órgão de imprensa, interessa aqui mais particularmente. Trata-se de um dos cinco textos que foram publicados em período imediatamente posterior ao quebra-quebra. $\mathrm{O}$ uso que então é feito desse material por Arthur Ramos tem a finalidade de esclarecer a influência do Exu-Leba no Brasil, e mais particularmente em Alagoas, já que, ali, esse orixá, que é identificado com o diabo católico, foi associado à figura do então governador Euclides Malta, frequentador assíduo dos xangôs do Estado. ${ }^{6}$

Trata-se de material muito irrelevante, se levarmos em conta a vasta produção cientifica desse alagoano, bem como a magnitude do episódio a que vimos nos referindo - o quebra de 1912. É certo que, nessa época, Arthur Ramos contava apenas sete anos, contudo, sua ligação com o Estado se manteve constante, mesmo depois de já ter alcançado grande projeção intelectual fora dali. 
Definitivamente, Arthur Ramos estava ocupado com questões mais gerais, como o problema da raça negra no Brasil, por exemplo. Contudo, apesar de não estar no centro de suas preocupações, o local não passou por ele totalmente despercebido, como deixam ver as matérias publicadas no Jornal de Alagoas, por ele reunidas para, entre outras coisas, denunciar as devassas que a polícia, vez por outra, realizava nos terreiros. Convém acrescentar que, nos dois casos em que esse material é por ele referido, primeiramente são destacados os aspectos do sincretismo religioso entre as "formas mais puras" de culto e as sobrevivências religiosas "menos interessantes", representadas pelo chamado "baixo espiritismo"; num segundo caso, para se referir à ligação entre os terreiros e a sociedade envolvente, inclusive por parte de segmentos mais aquinhoados, ao qual pertencia o governador Euclides Malta e seus asseclas.

Duas reflexões ressaltam desse material utilizado: a primeira delas diz respeito ao fato de que, com relação ao primeiro artigo, intitulado "Nos domínios da bruxaria", escrito pelo jornalista Pedro Paulo de Almeida, cujo teor preza pelo escárnio, como era comum em matérias dessa natureza, Arthur Ramos, ao mencioná-lo, incide numa falha apontada por críticos posteriores de sua obra, qual seja a de que, em função da exaltação da superioridade nagô, esse autor, dava prosseguimento a uma tendência iniciada por Nina Rodrigues, segundo a qual buscava-se caracterizar as etnias africanas usando de uma adjetivação valorativa que elevava aquele grupo étnico ao ápice de uma escala hierárquica por ele mesmo elaborada em detrimento dos bantos, colocados em condição de inferioridade. Assim, os nagôs: "eram altos, corpulentos, valentes, trabalhadores, de melhor índole e os mais inteligentes de todos". Enquanto os angolas "eram mais fracos, fisicamente, dos que os sudaneses. Loquazes, indolentes [e] muito festivos" (Ramos, 1971, p. 36-37).

Daí a crítica de que foi objeto, já que nessa sua escolha fica patente uma preferência pelos "melhores negros, sudaneses 
aristocratas, [que] ficaram na Bahia". Assim sendo, segundo Beatriz Góes Dantas:

[Arthur Ramos] termina deixando filtrar seu racismo ao escalonar os negros segundo graus de inteligência que aparecem associados a caracteres físicos, e também a sua postura elitista ao classificar como aristocráticos os negros sudaneses, grupo linguístico no qual se incluíam os nagôs, coincidentemente tidos como os negros mais inteligentes. (Dantas, 1988, p. 156-157).

Um segundo aspecto a analisar, toma como objeto de reflexão a segunda matéria sobre os xangôs alagoanos, mencionada em seu livro $O$ folclore negro brasileiro. Trata-se de uma das muitas que foram publicadas no mesmo jornal sob o titulo de "Bruxaria", no período imediatamente posterior à devassa aos terreiros de Maceió, conhecida também como "Operação Xangô". O conteúdo dessas matérias se caracteriza pelo desprezo por esse tipo de manifestação e um acentuado desdém.

Convém destacar que o motivo justificado por Arthur Ramos para a citação dessa matéria em seu trabalho, reside na ligação do então governador Euclides Malta com os xangôs do Estado. Enquanto que as matérias anteriores, publicadas no referido jornal entre os dias 4 e 8 de fevereiro daquele fatídico ano de 1912, enfatizam mais o modo como a população invadiu os terreiros, essa que foi escolhida por Arthur Ramos apenas menciona a ligação do Governador com as casas de xangô, pairando sobre o tema da perseguição um silêncio que passaria desapercebido ao leitor comum (Ramos, 1954, p. 2325).

Assim sendo, verifica-se acerca do assunto um incômodo silêncio, reflexo, talvez, da atitude assumida pelos próprios terreiros de Maceió que, por vários anos, ainda desenvolveriam aquela modalidade de rito tão bem descrita por Gonçalves Fernandes, quando da sua referida visita ao Estado, a qual é complementada com as seguintes informações: 
E com um cumprimento termina toda a cerimônia sem mais nada. Passou como uma visita de muita vergonha que quase não falou com as pessoas de casa - para quem observasse de longe. Só se ouviu mesmo o coxixo do dono da casa e si algumas atitudes um pouco extravagantes transpareceram, poderiam, no máximo, ser tomadas como um terço rezado em velório discreto. Uns coxixos e atitudes que não denunciam a pratica do novo xangô sem toque de atabaques, de agogô, sem toadas marcadas na noite, sem danças, tudo se passando como conversa baixa em quarto de morto. (Fernandes, 1941, p. 24).

Silêncio também do próprio Arthur Ramos e agora, não mais por uma questão de discrição ou fidelidade à tradição dos candomblés, à qual se mantinha ligado por vínculos iniciatórios, como foi dito acima. Mas de um tipo de silêncio que, como nos casos analisados por Michel Pollak, parece estar associado às lembranças traumatizantes, motivo pelo qual parece se impor a todos aqueles que querem evitar culpar as vítimas que também compartilham essa mesma lembrança comprometedora, motivo pelo qual também preferem guardar silêncio. No texto "Memória, esquecimento, silêncio", Pollack (1989) analisa três situações em que se verifica o que ele chama de "conflito e competição entre memórias concorrentes". Um desses casos, em particular, chama a atenção, por permitir uma aproximação com o caso em discussão. Trata-se do caso dos sobreviventes dos campos de concentração, os quais, após a libertação, retornaram aos seus locais de origem guardando silêncio sobre a experiência vivida. Segundo Pollak, essa estratégia estaria ligada à necessidade de encontrar uma forma razoável de viver entre os que, sob a forma de um consentimento tácito, assistiram à sua deportação. Essa atitude era ainda reforçada pela culpa que as próprias vítimas guardavam no fundo de si mesmas, pelo fato de que parte dessa comunidade, durante a ocupação nazista nos países em que antes habitavam, ter sido convocada a prestar importante colaboração na gestão de sua política anti-semita, como a preparação das listas dos futuros deportados ou até mesmo controle de certos locais de trânsito ou a organização do abastecimento nos comboios, embora com a 
possibilidade de negociar melhores condições de tratamento dos membros da comunidade atingidos pela política nazista:

Em face dessa lembrança traumatizante, o silêncio parece se impor a todos aqueles que querem evitar culpar as vítimas. E algumas vítimas, que compartilham essa mesma lembrança "comprometedora", preferem, elas também, guardar silêncio. (Pollack, 1989, p. 6).

Embora o caso alagoano refira-se a um tipo de violência de menores proporções, parece plausível pensar que o silêncio que se guardou sobre o quebra de 1912 está também associado a uma saída encontrada pelas vítimas e seus descendentes diante da condição de convívio a que se viram forçados com vizinhos e outros habitantes daquela comunidade, alguns dos quais tinham participado efetivamente do episódio da perseguição e com quem estavam fadados a manter vários tipos de relações. Sem contar o fato de que, até mesmo para os integrantes dessa modalidade religiosa, a relação com esse universo místico está cercada de embaraço, haja vista a identificação primordial com a Igreja Católica, através da associação em irmandades e da justificativa apresentada para a iniciação no culto dos orixás, a qual é apontada como uma exigência espiritual, cercada de ameaças de retaliação.

Em Alagoas, o silêncio também tem se verificado em outro contexto e em período mais recente. Conforme pesquisas realizadas sobre o mundo canavieiro alagoano - mais especificamente sobre a vida dos assalariados rurais e de suas famílias no interior do complexo sucroalcooleiro da Mata Norte do Estado de Alagoas -, percebe-se, por trás do quadro de extrema pobreza, das relações de trabalho e de dominação extremamente injustas, práticas de violência sendo atualizadas e cuja principal característica é a imposição do medo e do terror como forma de silenciar diante da verdade. No estudo sobre as múltiplas formas de linguagem engendradas pelos atores sociais na realidade canavieira de Alagoas, realizado por Geovani Jacó de Freitas (2003), tem-se no silêncio - juntamente com outras formas discursivas como os boatos, os cochichos, os contos orais, 
as ações metaforizadas -, "uma consciência possível dos agentes sociais dominados orientando um saber prático em conformidade com a vontade de viver desses agentes". Assim, esses mecanismos funcionam como "estratégia de sobrevivência entre a integridade física e a possibilidade de convivência coletiva possível".

Assim, o silêncio que pairou sobre os xangôs de Alagoas parece ter se alastrado sobre a intelectualidade local, que não dedicou ao assunto a atenção que ele merecia. A categoria que melhor se aplica a essa atitude intelectual é a do "esquecimento", a qual, no dizer de Dirceu Lindoso, em seu estudo sobre as rebeliões dos negros nas matas do Tombo Real, na fronteira entre os Estados de Pernambuco e Alagoas, significa "essa redução do poder da oralidade associada à reduzida escrita restauradora [e que] provocou uma descontinuidade na memória historiográfica". No caso da guerra insurrecional dos cabanos que ele analisa em particular, tal "esquecimento" funciona como uma elaboração da técnica da desmemória que alcançou toda a consciência social de uma região. Ou seja, para esse autor, a historiografia oficial, dita estamental, através daquilo que ele chama de "técnica gráfico-discursiva", tende a estender o espaço do empobrecimento ao espaço do esquecimento (Lindoso, 1983, p. 18).

Essa categoria não difere muito da que outros autores vêm trabalhando, ainda que sob outra denominação, como é o caso das idéias de "desconsideração" e "insulto moral". A primeira tem significado a rejeição e a desvalorização da identidade do outro e a segunda relaciona-se àquilo que não pode ser traduzido na linguagem de uma agressão a direitos legais, que não pode facilmente ser transformado numa indenização moral, mas que possui o mesmo efeito desestabilizador sobre a dignidade das vítimas. A obra que melhor sistematiza o uso dessas categorias é Direito legal e insulto moral, de Luis Roberto Cardoso de Oliveira, na qual esse autor busca, a partir de contextos socioculturais diversos, como Brasil, 
Estados Unidos e Quebec, uma articulação entre as dimensões legal e moral dos direitos. No caso da província canadense tem-se uma exacerbação do desrespeito à sua singularidade cultural, que resulta naquilo que o autor, inspirado em Charles Taylor (1994), chama de ato de desconsideração, para se referir àqueles atos que se traduzem "na rejeição ou na desvalorização da identidade do outro" (Oliveira, 2002, p. 50). Vejamos como Cardoso de Oliveira define essa categoria: "Prefiro falar em desconsideração ao invés da falta de reconhecimento para enfatizar o insulto moral que se faz presente quando a identidade do interlocutor é indisfarçavelmente, e por vezes incisivamente, não reconhecida".

Assim sendo, essa desconsideração da intelectualidade alagoana, ainda que inconsciente, refletida na sonegação dos fatos relativos ao quebra de 1912, bem como de todas as práticas associadas a um tipo de ator político específico, traduz-se numa forma de agressão que, apesar de não se confundir com o ato físico, de caráter criminal, deixa marcas indeléveis e também concorre para o aniquilamento de uma identidade autêntica sobre a qual pesam as mesmas consequências de uma atitude concreta.

\section{Conclusão}

$\mathrm{O}$ que se tentou aqui foi destacar as lacunas no pensamento de Arthur Ramos, inclusive aproximando-as de um tipo de "desconsideração" que soa até insultuosa. Contudo, não gostaria de encerrar esta reflexão deixando aqui apenas impressões um tanto quanto negativas acerca desse autor. Não há como negar a riqueza etnológica de sua obra, a qual foi produzida num curto espaço de tempo, já que a sua morte prematura nos privou de um rico material que certamente seria produzido na sequência do que já nos tinha sido proporcionado por sua inestimável capacidade intelectual. É claro que não cabem especulações, mas não é demais imaginar 
que, caso não tivesse nos deixado tão precocemente, sua atenção talvez pudesse ter se voltado para esse episódio tão representativo da história da violência em Alagoas e que tão pouca atenção recebeu dos estudiosos locais.

Assim, ficam valendo as palavras de Costa Pinto, contemporâneo de Arthur Ramos e com quem assumiria vários projetos em comum na década de 40: "A última lição ainda não foi dada, nem o será nunca, pois está contida na inspiração permanente de sua obra, repleta de sugestões e de veredas a serem aproveitadas e ampliadas pelos que, em qualquer tempo, sentirem, como ele sentiu, o fascínio irresistível da maior aventura a que se pode arriscar o espírito e que consiste em levar o método científico ao estudo das relações humanas".

\section{Notas}

1 Esta é a expressão pela qual os cultos afro-brasileiros são conhecidos nos Estados de Pernambuco e Alagoas, embora, como nos chama a atenção Yvonne Maggie, tais categorias não refletem a dinâmica das classificações fornecidas pelos próprios informantes, já que muitas vezes, numa única entrevista, percebemos a utilização de todas essas expressões por um informante para referir-se ao mesmo conjunto de práticas rituais. Até mesmo quanto ao termo "afro-brasileiro", que aqui utilizamos, seu uso deve estar cercado de precauções, como nos alerta Beatriz Góis Dantas, devido à propalada carga ideológica a ele associada, mas que, como ela, continuamos utilizando, na falta de um outro mais satisfatório. Em tempo, sempre que o termo xangô aparecer relacionado à entidade religiosa, como é o caso quando é utilizado para referir-se às casas de culto naqueles Estados, a expressão aparecerá grafada com a letra inicial maiúscula, enquanto que, quando tratar-se da prática em si, o termo aparecerá grafado sem maiúscula (cf. Maggie, 1975; Dantas, 1988).

2 A obrigação de dissimular as práticas religiosas deu margem a que se utilizassem ou se improvisassem instrumentos mais silenciosos, 
como o que foi anotado por Reis $(1987$, p. 99) no calundu do Pasto de Cachoeira, em 1785.

3 O ogã, segundo o próprio Arthur Ramos (1951, p. 283) “é uma espécie de protetor do terreiro, pessoa influente, que se submete a uma rápida iniciação e se compromete a contribuir para as despesas do candomblé e a cumprir outras obrigações.

4 Sobre esse aspecto do trabalho de campo, mais precisamente sobre a relação observador-observado em comunidades religiosas afrobrasileiras, cf. Silva (2000).

5 No livro Os africanos no Brasil, o médico maranhense Nina Rodrigues (1932) nos oferece, tendo também os jornais como fonte, algumas das páginas mais impressionantes sobre a relação entre os terreiros baianos e os órgãos repressivos do Estado.

6 Abelardo Duarte (1974, p. 17) lembra a improcedência das informações prestadas por Arthur Ramos, que havia confiado nas reportagens imaginárias do jornal oposicionista, publicadas com a finalidade de execrar publicamente os correligionários do Partido Republicano do Estado, chefiado por Euclides Malta (cf. Ramos, 1954, p. 23-25).

\section{The 'Non-Said' in the work of Arthur Ramos}

Abstract: The purpose of this article is to discuss in the light of Arthur Ramos' work, particularly concerning anthropological studies of Afro-Brazilian religions, the reason why this Brazilian author dedicated so little attention to the Shango of his country, making reference to the persecution suffered by worship houses of Maceió city, in 1912, only superficially and without the concern to investigate the motivations of the episode which was called by its practitioners "Operation Shango".

Keywords: Arthur Ramos, Operation Shango, Afro-Brazilian religions. 


\section{Referências bibliográficas}

BASTIDE, Roger. As religiões africanas no Brasil. São Paulo: Perspectiva, 1971.

DANTAS, Beatriz Góes. Vovó nagô e papai branco: usos e abusos da África no Brasil. Rio de Janeiro: Graal, 1988.

DUARTE, Abelardo. Catalogo ilustrado da Coleção Perseverança. Maceió: Deca, 1974.

FERNANDES, Gonçalves. O sincretismo religioso no Brasil. São Paulo: Guairá, 1941.

FREITAS, Geovani Jacó de. Ecos da violência: narrativas e relações de poder no Nordeste canavieiro. Rio de Janeiro: Relume Dumará, 2003.

LINDOSO, Dirceu. Utopia armada: rebelião de pobres nas matas do Tombo Real (1832-1850). Rio de Janeiro: Paz e Terra, 1993.

MAGGIE, Yvonne. Guerra de Orixá: um estudo de ritual e conflito. Rio de Janeiro: Zahar, 1975.

OLIVEIRA, Luis Roberto Cardoso de. Direito legal e insulto moral: dilemas da cidadania no Brasil, Quebec e Estados Unidos. Rio de Janeiro: Relume Dumará, 2002.

POLLAK, Michael. Memória, esquecimento, silêncio. Estudos históricos, Rio de Janeiro. v. 2, n. 3, p. 3-15, 1989. Disponível em: <http://www.cpdoc.fgv.br/revista/arq/43.pdf>.

RAFAEL, Ulisses Neves. Xangô rezado baixo: um estudo da perseguição aos terreiros de Alagoas em 1912. 2004. 274 f. Tese (Doutorado em Sociologia e Antropologia) Universidade Federal do Rio de Janeiro, 2004.

RAMOS, Arthur. O folclore negro brasileiro. São Paulo: Gráfica Carioca, 1945.

. O negro brasileiro. Recife: Massagana, 1988.

. O negro na civilização brasileira. Rio de Janeiro: Casa do Estudante do Brasil, 1971. 
RAMOS, Arthur. Introdução à Antropologia brasileira. Rio de Janeiro: Casa do Estudante do Brasil, 1989.

REIS, João José. Magia jeje na Bahia: a invasão do calundu do Pasto de Cachoeira, 1785. Revista Brasileira de História. São Paulo, v. 8, n. 16, mar. 1988.

RIBEIRO, René. Introdução. In: RAMOS, Arthur. O negro brasileiro. Recife: Massagana, 1988.

RODRIGUES, Nina. Os africanos no Brasil. São Paulo: Companhia Editora Nacional, 1932.

SILVA, Vagner Gonçalves. Observação participante e escrita etnográfica. In: FONSECA, Maria Nazareth Soares (Org.). Brasil afro-brasileiro. Belo Horizonte: Autêntica, 2000. p. 285-306.

TAYLOR, Charles. The politics of recognition. In: GUTMANN, A. (Org.). Multiculturalism and the politics of recognition. Nova Jersey: Princeton University Press, 1994. 